Article

\title{
An Unsymmetrical Trinickel Metal Complex with 4-Sulfobenzoate Axial Ligand: $\left[\mathrm{Ni}_{3}(\mathrm{dpa})_{4}(4-\mathrm{sb})\left(\mathrm{H}_{2} \mathrm{O}\right)\right] \cdot 3 \mathrm{H}_{2} \mathrm{O}$
}

\author{
Xiao-Feng Zheng and Long-Guan Zhu * \\ Department of Chemistry, Zhejiang University, Hangzhou 310027, China; \\ E-Mail: xiaofengzheng004@163.com \\ * Author to whom correspondence should be addressed; E-Mail: chezlg@ zju.edu.cn; \\ Tel.: +86-571-87963867; Fax: +86-571-87951895.
}

Received: 15 April 2011; in revised form: 20 July 2011 / Accepted: 29 July 2011 /

Published: 5 August 2011

\begin{abstract}
An unsymmetrical trinickel metal complex, $\left[\mathrm{Ni}_{3}(\mathrm{dpa})_{4}(4-\mathrm{sb})\left(\mathrm{H}_{2} \mathrm{O}\right)\right] \cdot 3 \mathrm{H}_{2} \mathrm{O}(\mathbf{1})$, where dpa is a 2,2'-dipyridylamine anion and 4-sb is 4-sulfobenzoate dianion, was synthesized and characterized by X-ray crystallography, IR, elemental analysis, fluorescence, and cyclic voltammetry. The molecular structure of $\mathbf{1}$ is a cluster with a linear trimer. The extended structure is a 3D architecture assembled by hydrogen bonds. The 4-sulfobenzoate axial replacement leads to the change of Ni-Ni distances, the shift of the fluorescence emission, and the reversible one-electron reduction process without oxidation process.
\end{abstract}

Keywords: trinickel complex; unsymmetrical complex; cyclic voltammogram; fluorescence property

\section{Introduction}

Nearly 30 trinickel metal complexes with 2,2'-dipyridylamine (dpa) ligands have been prepared since 1991 [1]. However, only two complexes with different axial ligands were reported, $\left[\mathrm{Ni}_{3}(\mathrm{dpa})_{4}\left(\mathrm{CH}_{3} \mathrm{CN}\right)\right]\left(\mathrm{PF}_{6}\right)\left(2 \mathrm{CH}_{2} \mathrm{Cl}_{2}\right)$ (2) and $\left[\mathrm{Ni}_{3}(\mathrm{dpa})_{4}(\mathrm{Cl})\left(\mathrm{ClO}_{4}\right)\right] \cdot \mathrm{CH}_{2} \mathrm{Cl}_{2}$ (3) [2,3]. Complex 2 was unexpectedly obtained from re-crystallization of $\left.\left[\mathrm{Ni}_{3}(\mathrm{dpa})_{4}\left(\mathrm{CH}_{3} \mathrm{CN}\right)_{2}\right]\right]\left(\mathrm{PF}_{6}\right)_{2}$ in dichloromethane [2]. Complex 3 was synthesized by control of the ratio of starting materials and reaction time [3]. Axial 
ligands in trinickel complexes can largely influence the structural parameters and properties [4], for example complex $\mathbf{2}$ has an unusual magnetic property; therefore synthesis of new unsymmetrical trinickel complexes can provide more examples to help understand the influence of structures on their properties. Herein, we report a new unsymmetrical trinickel complex with the 4-sulfobenzoate (4-sb) ligand, namely $\left[\mathrm{Ni}_{3}(\mathrm{dpa})_{4}(4-\mathrm{sb})\left(\mathrm{H}_{2} \mathrm{O}\right)\right] \cdot 3 \mathrm{H}_{2} \mathrm{O}(\mathbf{1})$.

\section{Results and Discussions}

The unusual character of complex $\mathbf{1}$ is an unsymmetrical trinickel complex. The molecular structure of $\mathbf{1}$ is shown in Figure 1 and selected bond lengths and angles are listed in Table 1. The trinickel unit of $\left[\mathrm{Ni}_{3}(\mathrm{dpa})_{4}\right]^{2+}$ is wrapped by four dpa ligands. The two axial sites of the $\left[\mathrm{Ni}_{3}(\mathrm{dpa})_{4}\right]^{2+}$ are occupied by the 4-sb ligand and water molecule, respectively. The Ni-Ni distances [2.424(1) and 2.427(1) $\mathrm{A}]$ in 1 are longer than those of the $\left[\mathrm{Ni}_{3}(\mathrm{dpa})_{4}\left(\mathrm{H}_{2} \mathrm{O}\right)_{2}\right]^{2+}$ moiety [2.390 $\AA$ and $\left.2.392 \AA\right]$ [5], and significantly longer than those of 2 [2.340(1) and 2.355(1) $\AA$ ] and 3 [2.370(2) and 2.421(2) $\mathrm{A}$ ], indicating the 4-sb axial ligand lengthens the $\mathrm{Ni}-\mathrm{Ni}$ distances. The $\mathrm{Ni}-\mathrm{Ni}$ distances are also longer than those in complex with caroxylate ligands of $\left[\mathrm{Ni}_{3}(\mathrm{dpa})_{4}(\mathrm{L1})_{2}\right] \cdot\left(\mathrm{H}_{2} \mathrm{O}\right) \cdot \mathrm{C}_{2} \mathrm{H}_{5} \mathrm{OH} \quad$ (4) $[2.4162(4) \AA]$ (L1 = 3-(2-hydroxyl-phenyl)-acrylate) [6]. In complexes $\mathbf{2}$ and 3, Ni-Ni distances are different; while in complex 1 the unsymmetrical axial coordination does not lead to the extinct difference of Ni-Ni distances. The lengths of trinickel linear species in 1-3 are $4.851 \AA$, $4.791 \AA$, and $4.694 \AA$, respectively. In the trinickel core $\left[\mathrm{Ni}_{3}(\mathrm{dpa})_{4}\right]^{2+}$, the average Ni-N distance for two terminal Ni ions is $2.089 \AA$ and the average central Ni-N distance is $1.904 \AA$. These average Ni-N distances are very similar to those of other trinickel metal complexes [7-10], illustrating that the axial ligands only tune the Ni-Ni distances through the self-adjustment of the structural parameters of the helix.

The two axial ligands of 4-sb and water have potential hydrogen bonding ability, therefore the extended hydrogen bonding structure is a 3D architecture (Figure 2).

Figure 1. View of molecular structure of $\mathbf{1}$. $\mathbf{H}$ atoms and lattice water molecules are omitted for clarity.

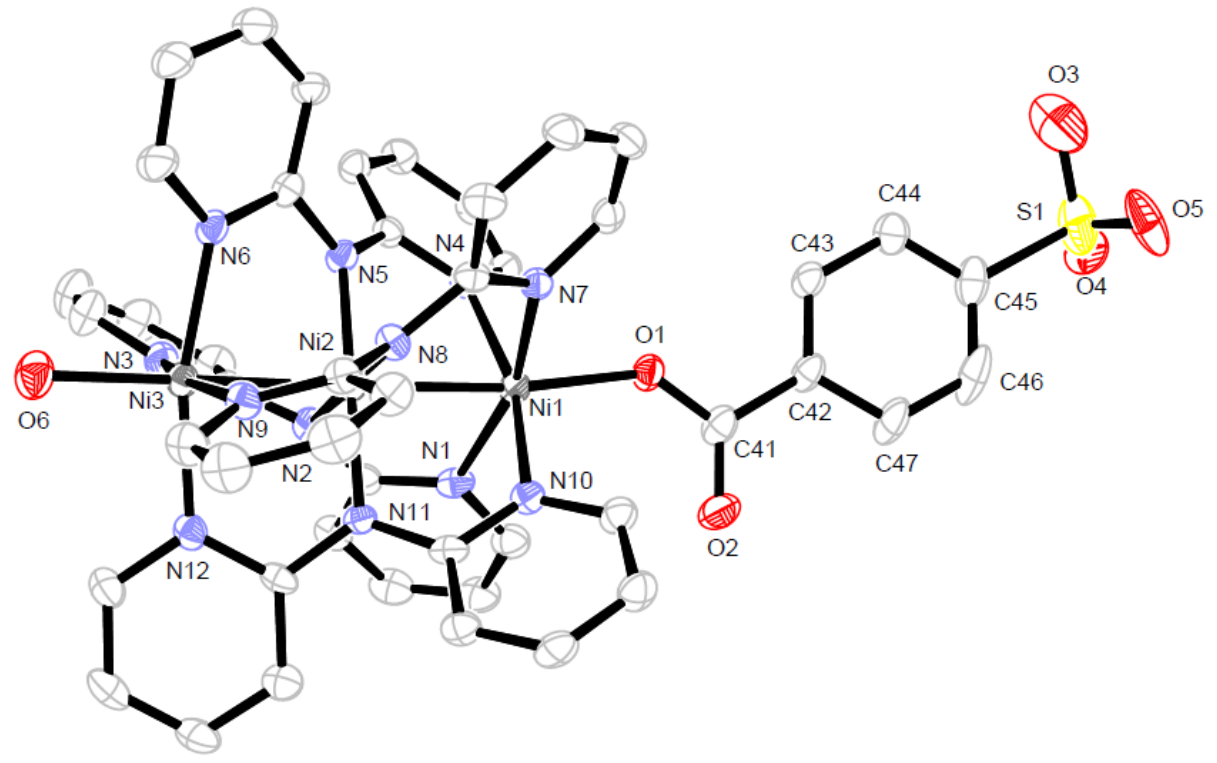


Figure 2. View of the 3-D hydrogen-bonding architecture of $\mathbf{1}$.

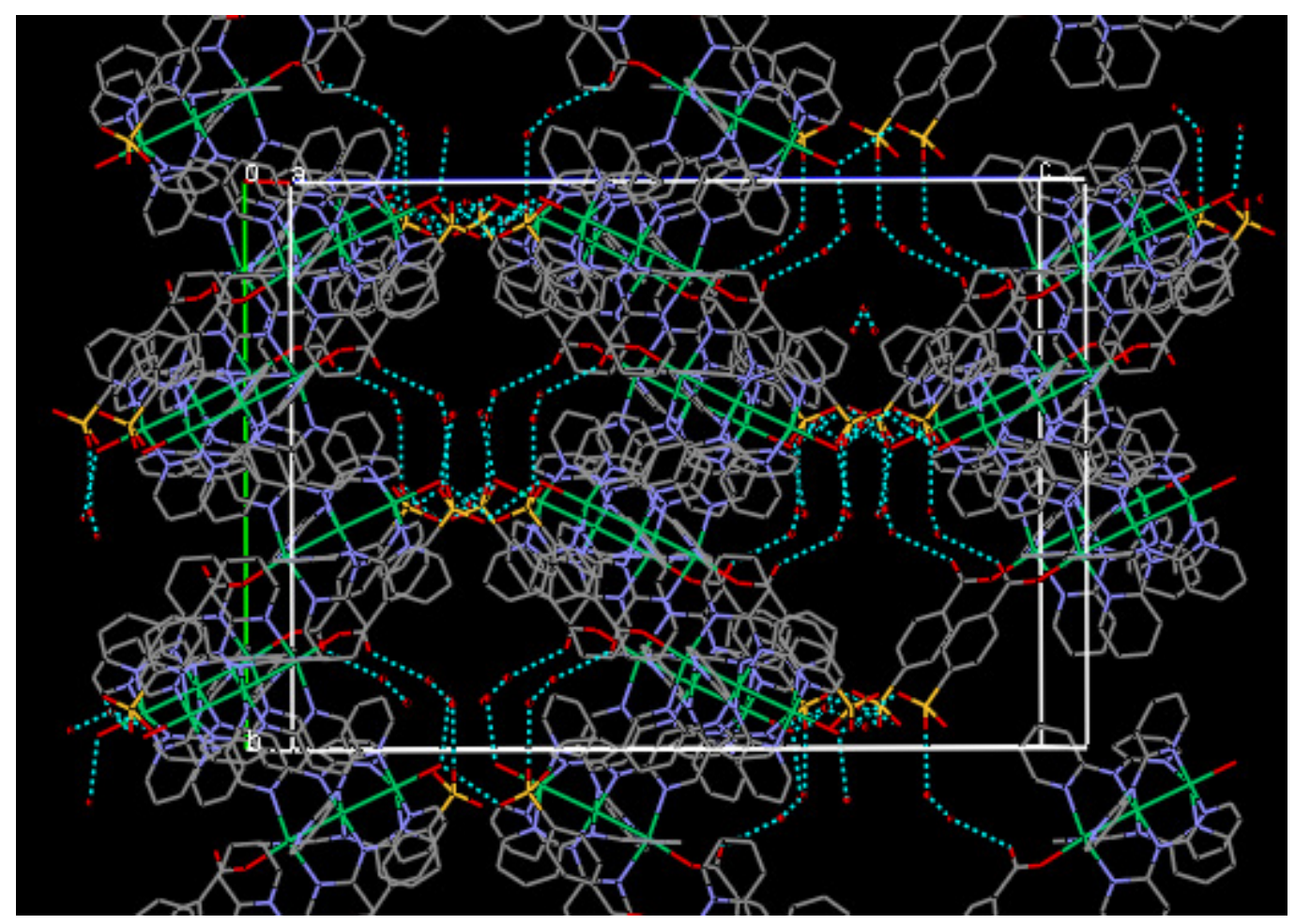

Table 1. Selected bond lengths $(\AA)$ and angles $\left(^{\circ}\right)$ for complex $\mathbf{1}$.

\begin{tabular}{llll}
\hline Ni1-Ni2 & $2.427(1)$ & Ni1-N1 & $2.109(7)$ \\
Ni2-Ni3 & $2.424(1)$ & Ni1-N4 & $2.088(6)$ \\
Ni1-N7 & $2.110(7)$ & Ni1-N10 & $2.074(6)$ \\
Ni1-O1 & $2.036(5)$ & Ni2-N2 & $1.904(7)$ \\
Ni2-N8 & $1.909(6)$ & Ni2-N11 & $1.906(6)$ \\
Ni2-N5 & $1.895(6)$ & Ni3-N3 & $2.072(5)$ \\
Ni3-N6 & $2.059(5)$ & Ni3-N12 & $2.099(7)$ \\
Ni3-N9 & $2.099(7)$ & Ni3-O6 & $2.061(7)$ \\
N1-Ni1-N4 & $87.5(2)$ & N1-Ni1- N7 & $163.8(3)$ \\
N1-Ni1- N10 & $90.4(2)$ & N1-Ni1-O1 & $103.7(3)$ \\
N4-Ni1-N7 & $89.3(2)$ & N4-Ni1-N10 & $164.4(2)$ \\
N4-Ni1-O1 & $92.5(2)$ & N7-Ni1-N10 & $88.3(2)$ \\
N7-Ni1-O1 & $92.3(2)$ & N10-Ni1-O1 & $103.1(2)$ \\
N2-Ni2-N5 & $89.5(3)$ & N2Ni2-N8 & $178.6(3)$ \\
N2-Ni2-N11 & $90.2(3)$ & N5-Ni2-N8 & $89.4(3)$ \\
N5-Ni2-N11 & $179.4(3)$ & N8-Ni2-N11 & $90.9(3)$ \\
N3-Ni3-N6 & $88.3(3)$ & N3-Ni3-Ni9 & $165.8(3)$ \\
N3-Ni3-N12 & $91.6(3)$ & N3-Ni3-O6 & $97.8(3)$ \\
N6-Ni3-N9 & $89.4(3)$ & N6-Ni3-N12 & $165.6(2)$ \\
N6-Ni3-O6 & $97.8(3)$ & N9-Ni3-N12 & $87.2(3)$ \\
N9-Ni3-O6 & $96.4(3)$ & N12-Ni3-O6 & $96.5(3)$ \\
Ni1-Ni2-Ni3 & $178.13(6)$ & & \\
\hline
\end{tabular}


The fluorescent spectrum of 1 shows emission bands at $413 \mathrm{~nm}, 438 \mathrm{~nm}, 453 \mathrm{~nm}$ and $470 \mathrm{~nm}$ $\left(\lambda_{\text {ex }}=220 \mathrm{~nm}\right.$ ) in the solid state at room temperature (Figure 3). The maximal peak is at $413 \mathrm{~nm}$. Comparison of emission bands between $\mathbf{1}$ and ligands suggests that the origin of these emissions is mainly caused by $\mathrm{dpa}^{-}$and $4-\mathrm{sb}^{2-}$ ligands and their emission strength is stronger than those of free ligands. The strongest peaks in $\mathbf{1},\left[\mathrm{Ni}_{3}(\mathrm{dpa})_{4} \mathrm{Cl}_{2}\right](421 \mathrm{~nm}, 452 \mathrm{~nm}, 470 \mathrm{~nm})$ [11], and $\left[\mathrm{Ni}_{3}(\mathrm{dpa})_{4}(\mathrm{Cl})\left(\mathrm{ClO}_{4}\right)\right]\left(\mathrm{CH}_{2} \mathrm{Cl}_{2}\right)(417 \mathrm{~nm}, 453 \mathrm{~nm}$, and $470 \mathrm{~nm})$ are somewhat different and shifted, illustrating that different axial ligands truly affect the fluorescent properties.

Figure 3. The fluorescent spectrum of $\mathbf{1}$.

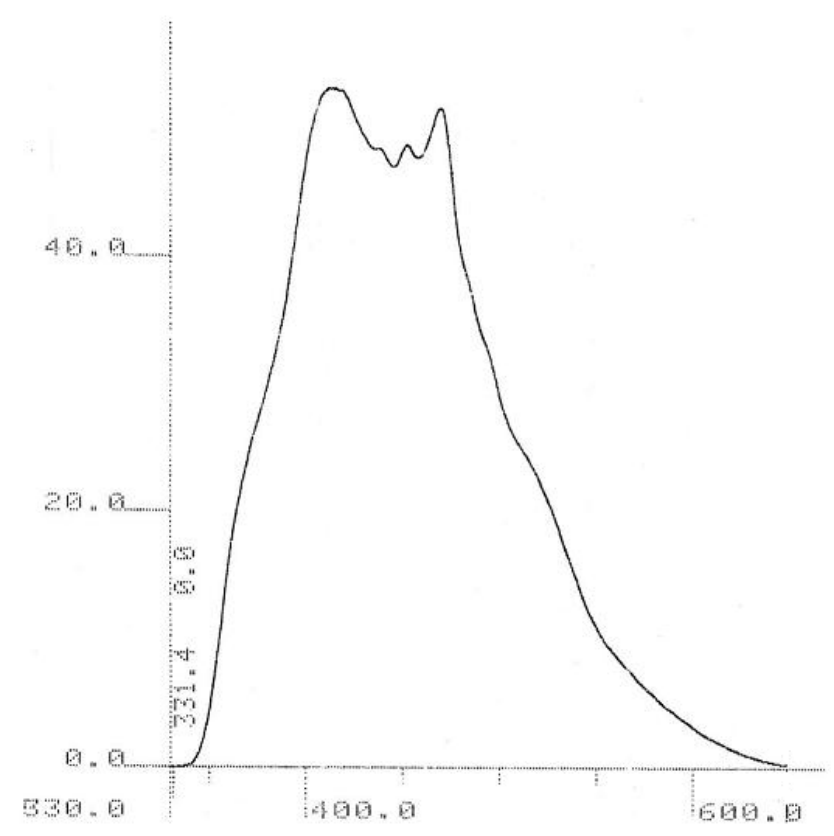

Figure 4. The spectrum of CV (Cyclic Voltammogram) for complex 1 in DMSO.

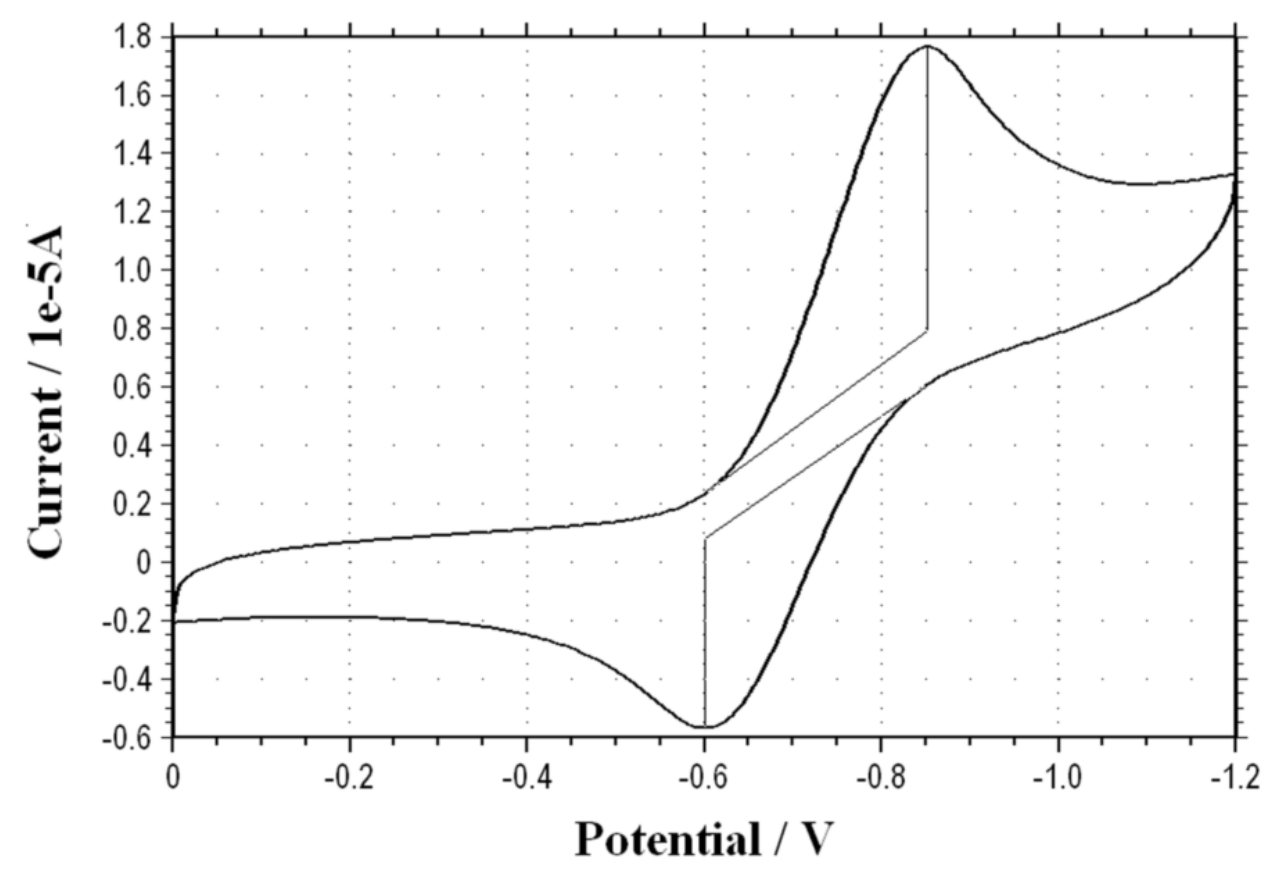


The electrochemical spectrum of $\mathbf{1}$ in DMSO solution with $0.1 \mathrm{M}$ TBAP as the supporting electrolyte is shown in Figure 4. We noted that there is no oxidation process for $\mathbf{1}$ in the measurement range of 1.2 -1.2 $\mathrm{V}$ and a reversible one-electron reduction process was found according to the explanation of Cotton and his co-workers [12]. The reduction site is at $-0.85 \mathrm{~V}$ and the $E_{1 / 2}$ is $-0.726 \mathrm{~V}$. The electrochemical behavior of $\mathbf{1}$ is different from those of other trinickel complexes such as $\left[\mathrm{Ni}_{3}(\mathrm{dpa})_{4} \mathrm{Cl}_{2}\right]$ and $\left[\mathrm{Ni}_{3}(\mathrm{dpa})_{4}\left(\mathrm{ClO}_{4}\right)(\mathrm{Cl})\right] \cdot 2 \mathrm{CH}_{2} \mathrm{Cl}_{2}$. Such unusual property was also found in the trinickel complexes with di(2-pyrazyl)amine ligands of $\left[\mathrm{Ni}_{3}(\mathrm{dpza})_{4} \mathrm{Cl}_{2}\right]$ and $\left[\mathrm{Ni}_{3}(\mathrm{dpza})_{4}(\mathrm{NCS})_{2}\right]$ [13].

\section{Experimental Section}

\subsection{Materials and synthesis}

2,2'-Dipyridylamine (Hdpa), $\left[\mathrm{Ni}_{3}(\mathrm{dpa})_{4} \mathrm{Cl}_{2}\right]$, and $\left[\mathrm{Ni}_{3}(\mathrm{dpa})_{4}\left(\mathrm{ClO}_{4}\right)_{2}\right]$ were prepared according to previous reports $[1,3,4]$. Other chemicals used in the experiments were obtained from commercial sources. IR spectrum was recorded by a Nicolet Nexus 470 infrared spectrophotometer in KBr pellet. Elemental analyses for C, H, and N were done on a Flash EA 1112 analyzer. The fluorescent spectrum was determined using a Shimadzu RF-50 spectrometer on a powdered sample in the solid state at room temperature. Cyclic voltammogram was carried out on a $\mathrm{CHI} 600 \mathrm{C}$ potentiostat and the detailed operation and experimental conditions were described in our previous reports $[1,3,4]$.

Complex 1 was prepared by the use of a three layered-solution technique. In a slender tube with a diameter of $0.8 \mathrm{~cm}$, the bottom layer was $6 \mathrm{~mL}$ of aqueous solution containing 4-sulfobenzoic acid potassium $(0.05 \mathrm{~mol} / \mathrm{L})$ and $\mathrm{AgNO}_{3}(0.05 \mathrm{~mol} / \mathrm{L})$, the middle layer was $6 \mathrm{~mL}$ of $\mathrm{CH}_{3} \mathrm{OH}-\mathrm{H}_{2} \mathrm{O}$ with a volume ratio of $1: 1$, and the upper layer was $6 \mathrm{~mL}$ of methanol containing $\left[\mathrm{Ni}_{3}(\mathrm{dpa})_{4}\left(\mathrm{ClO}_{4}\right)_{2}\right]$ $(0.0125 \mathrm{~mol} / \mathrm{L})$. Two weeks later, dark purple block crystals were obtained. Yield: $56 \%$. Anal. Calc for $\mathrm{C}_{47} \mathrm{H}_{44} \mathrm{~N}_{12} \mathrm{Ni}_{3} \mathrm{O}_{9} \mathrm{~S}(\mathrm{Mr}=1129.13)$ : C: $50.00, \mathrm{H}: 3.94, \mathrm{~N}: 14.88 \%$; found C: $50.83, \mathrm{H}: 3.65, \mathrm{~N}: 14.59 \%$. IR (KBr pellet, cm ${ }^{-1}$ ): 3427 m, 1604 s, 1550 m, 1469 s, 1425 s, 1383 w, 1358 s, 1313 m, 1284 w, 1265 w, 1240 w, 1179 w, 1155 m, 1113 w, 1035 w, 1012 m, 927 w, 894 w, 870 w, 840 w, 765 m, 739 m, $702 \mathrm{w}, 671 \mathrm{w}, 639 \mathrm{w}$. TG analysis for 1 showed that the first-step weight loss was observed from room temperature to $167{ }^{\circ} \mathrm{C}$. The weight loss of $6.88 \%$ corresponds to the release of four $\mathrm{H}_{2} \mathrm{O}$ molecules (calculated 6.38\%). Complex 1 began to decompose at $380{ }^{\circ} \mathrm{C}$.

So far, there is no common strategy to prepare unsymmetrical trinickel complexes. In the formation of $\mathbf{1}, \mathrm{AgNO}_{3}$ is necessary because its absence does not lead to complex $\mathbf{1}$, instead a symmetric complex with two same axial ligands. The addition of other salts such as copper salt also could not precipitate the complex 1.

\subsection{Crystallographic determination}

Data collection for a suitable crystal of complex 1 were carried out using a Bruker SMART APEX CCD detector with graphite-monochromatized Mo-K $\alpha$ radiation $(\lambda=0.71073 \AA)$. The data frames were integrated by the SAINT program [14]. Empirical absorption correction was done by the SADABS program [15]. The structure was solved by the Patterson method and successive Fourier synthesis, and refined by the full-matrix least squares method on $\mathrm{F}^{2}$. All non-hydrogen atoms were 
anisotropically refined. Hydrogen atoms on carbon atoms were placed in calculated positions and refined as riding, with $\mathrm{C}-\mathrm{H}=0.93 \AA$ and $\mathrm{U}_{\text {iso }}(\mathrm{H})=1.2 \mathrm{U}_{\mathrm{eq}}(\mathrm{C})$. All of the programs used are included in the WinGX Suite version 1.70 [16]. The drawings of the molecule were realized with the help of ORTEP-3 for Windows [17].

Further details of the crystal structure investigation may be obtained free of charge from http://www.ccdc.cam.ac.uk/conts/retrieving.html, or from the Cambridge Crystallographic Data Centre, 12 Union Road, Cambridge CB2 1EZ, UK; fax: (+44) $1223 \quad 336$ 033; or E-Mail: deposit@ccdc.cam.ac.uk. upon quoting the 796463 CCDC number. Detailed crystallographic data and structure refinements of complex 1 are listed in Table 2.

Table 2. Crystallographic data and refinement parameters for complex 1.

\begin{tabular}{ll}
\hline Formula & $\mathrm{C}_{47} \mathrm{H}_{44} \mathrm{~N}_{12} \mathrm{Ni}_{3} \mathrm{O}_{9} \mathrm{~S}$ \\
$\mathrm{Mr}$ & 1129.13 \\
Crystal color/shape & Dark purple/block \\
Crystal size/mm & $0.30 \times 0.30 \times 0.25$ \\
Space group & Orthorhombic, Pbcn \\
$a / \AA$ & $15.4384(12)$ \\
$b / \AA$ & $22.3183(16)$ \\
$c / \AA$ & $31.781(2)$ \\
$\alpha{ }^{\circ}$ & 90 \\
$\beta /^{\circ}$ & 90 \\
$\mathcal{H}^{\circ}$ & 90 \\
$V / \AA^{3}$ & $10950.4(13)$ \\
$Z$ & 8 \\
$D /$ g.cm & \\
$\mathrm{T} / \mathrm{K}$ & 1.370 \\
$\mu /$ mm $^{-1}$ & $295(2)$ \\
$\theta \quad$ range/ & 1.121 \\
Measured reflections & $3.2 \sim 25.1$ \\
Unique reflections & 67491 \\
Observed reflections & 9942 \\
$\mathrm{~F}(000)$ & 5213 \\
$\mathrm{R} 1$ and wR2 (I $>2 \sigma(\mathrm{I}))$ & 4688 \\
$\mathrm{R} 1$ and wR2 (all data) & $0.074,0.203$ \\
Number of variables & $0.151,0.260$ \\
$\mathrm{GOF}$ & 669 \\
Largest difference peak and hole/e. $\AA^{-3}$ & 0.972 \\
\hline
\end{tabular}

\section{Conclusions}

In conclusion, an unsymmetrical trinickel metal complex $\left[\mathrm{Ni}_{3}(\mathrm{dpa})_{4}(4-\mathrm{sb})(\mathrm{H} 2 \mathrm{O})\right] \cdot\left(3 \mathrm{H}_{2} \mathrm{O}\right)(\mathbf{1})$ was synthesized. The axial ligands influence the Ni-Ni distances, fluorescence properties and the cyclic voltammogram of $\mathbf{1}$. The maximal emission peak in $\mathbf{1}$ is shifted compared with those of $\left[\mathrm{Ni}_{3}(\mathrm{dpa})_{4} \mathrm{Cl}_{2}\right]$ and $\left[\mathrm{Ni}_{3}(\mathrm{dpa})_{4}(\mathrm{ClO})(\mathrm{Cl})\right] \cdot 2 \mathrm{CH}_{2} \mathrm{Cl}_{2}$. The cyclic voltammogram is largely different from those of other trinickel complexes such as $\left[\mathrm{Ni}_{3}(\mathrm{dpa})_{4} \mathrm{Cl}_{2}\right]$ and $\left[\mathrm{Ni}_{3}(\mathrm{dpa})_{4}\left(\mathrm{ClO}_{4}\right)(\mathrm{Cl})\right] \cdot 2 \mathrm{CH}_{2} \mathrm{Cl}_{2}$. 


\section{Acknowledgments}

This work was supported by the Zhejiang Provincial Natural Science Foundation of China (grant No. Z407036), the National Natural Science Foundation of China (grant No. 20573092).

\section{References}

1. Zhang, J.; Zhu, L.G. Synthesis, Structures, and Properties of Three Coordination Compounds Based on Trinickel Clusters Extended by Phenyldicarboxylate Ligands. CrystEngComm 2011, 13, 553-560.

2. Cotton, F.A.; Murillo, C.A.; Wang, Q.S.; Young, M.D. Unusual Magnetism of an Unsymmetrical Trinickel Chain. Eur. J. Inorg. Chem. 2008, 5257-5256.

3. Miao, X.H.; Zhu, L.G. Synthesis, Structure, and Cyclic Voltammetric Property of Metal String Complex $\left[\mathrm{Ni}_{3}(\mathrm{dpa})_{4}\left(\mathrm{ClO}_{4}\right)(\mathrm{Cl})\right] \cdot \mathrm{CH}_{2} \mathrm{Cl}_{2}$. Z. Anorg. Allg. Chem. 2010, 636, 878-881.

4. Miao, X.H.; Zhu, L.G. Influence of Axial Ligands and Anions on the Ni-Ni Distances in Trinickel String Complexes: Synthesis, Structure, and Properties of $\left[\mathrm{Ni}_{3}(\mathrm{dpa})_{4}\left(\mathrm{CH}_{3} \mathrm{CN}\right)_{2}\right]$. $\left(\mathrm{ClO}_{4}\right)_{2} \cdot\left(\mathrm{CH}_{3} \mathrm{CN}\right) \cdot \mathrm{H}_{2} \mathrm{O}$. J. Coord. Chem. 2010, 63, 3816-3823.

5. Li, H.; Lee, G.H.; Peng, S.M. The First One-dimensional Coordination Polymer Containing $\mathrm{O}-\mathrm{H} . . . \mathrm{F}-\mathrm{Ni}$ Hydrogen Bonding: Crystal Structure of $\left[\mathrm{Ni}_{3}(\mathrm{dpa})_{4} \mathrm{~F}_{2}\right]\left[\mathrm{Ni}_{3}(\mathrm{dpa})_{4}\left(\mathrm{H}_{2} \mathrm{O}\right)_{2}\right]$ $\left(\mathrm{BF}_{4}\right)_{2} .2 \mathrm{CH}_{3} \mathrm{OH}$. Inorg. Chem. Commun. 2003, 6, 1-4.

6. Li, H.; Yan, J.; Xu, Y.Y.; Gao, W.G.; Lee, G.H.; Peng, S.M. Hydrogen-bonded Assemblies of Trinuclear Metal String Complexes. J. Coord. Chem. 2007, 60, 2731-2738.

7. Berry, J.F.; Cotton, F.A.; Daniels, L.M.; Murillo, C.A. A Trinickel Dipyridylamido Complex with Metal-Metal Bonding Interaction: Prelude to Polynickel Molecular Wires and Devices? J. Am. Chem. Soc. 2002, 124, 3212-3213.

8. Cotton, F.A.; Chao, H.; Li, Z.; Murillo, C.A.; Wang, Q.S. Effect of Axial Anthracene Ligands on the Luminescence of Trinickel Molecular Wires. J. Organomet. Chem. 2008, 693, 1412-1419.

9. Clerac, R.; Cotton, F.A.; Dunbar, K.R.; Murillo, C.A.; Pascual, I.; Wang, X.P. Further Study of the Linear Trinickel(II) Complex of Dipyridylamide. Inorg. Chem. 1999, 38, 2655-2657.

10. Peng, C.H.; Wang, C.C.; Lee, H.C.; Lo, W.C.; Lee, G.H.; Peng, S.M. Two Polymeric Linear Tri-nickel(II) Complexes: $\left[\mathrm{Ni}_{3}(\mathrm{dpa})_{4}\left(\mathrm{C}_{4} \mathrm{O}_{4} \mathrm{Me}\right)\right]_{\mathrm{n}}\left(\mathrm{BF}_{4}\right)_{\mathrm{n}}$ and $\left[\mathrm{Ni}_{3}(\mathrm{dpa})_{4}\left(\mathrm{~N}_{3}\right)\right]_{\mathrm{n}}\left(\mathrm{PF}_{6}\right)_{\mathrm{n}}$ Synthesis, Structural Characterization and Magnetic Properties. J. Chin. Chem. Soc. 2001, 48, 987-996.

11. Berry, J.F.; Cotton, F.A.; Daniels, L.M.; Murillo, C.A.; Wang, X.P. Oxidation of $\mathrm{Ni}_{3}(\mathrm{dpa})_{4} \mathrm{Cl}_{2}$ and $\mathrm{Cu}_{3}(\mathrm{dpa})_{4} \mathrm{Cl}_{2}$ : Nickel-Nickel Bonding Interaction, but No Copper-Copper Bonds. Inorg. Chem. 2003, 42, 2418-2427.

12. Berry, J.F.; Cotton, F.A.; Murillo, C.A. Making Connections with Molecular Wires: Extending Tri-nickel Chains with Axial Cyanide, Dicyanamide, and Phenylacetylide Ligands. Dalton Trans. 2003, 3015-3021.

13. Ismayilov, R.H.; Wang, W.Z.; Lee, G.H.; Wang, R.R.; Liu, I.P.C.; Yeh, C.Y.; Peng, S.M. New Versatile Ligand Family, Prazine-Modulated Oligo- $\alpha$-Pyridylamino Ligands, from Coordination Polymer to Extended Metal Atom Chains. Dalton Trans. 2007, 2898-2907.

14. Bruker Analytical X-ray Instruments, Inc. SAINT; Bruker Analytical X-ray Instruments, Inc.: 
Madison, WI, USA, 2002.

15. Bruker Advanced X-ray Solution, Inc. SADABS, Version 2.05.; Bruker Advanced X-ray Solution, Inc.: Madison, WI, USA, 2000.

16. Farrugia, L.J. WINGX, A Windows Program for Crystal Structure Analysis; University of Glasgow: Glasgow, Great Britain, 1998.

17. Farrugia, L.J. ORTEP-3 for Windows-A Version of ORTEP-III with a Graphical User Interface. J. Appl. Cryst. 1997, 30, 565-565.

(C) 2011 by the authors; licensee MDPI, Basel, Switzerland. This article is an open access article distributed under the terms and conditions of the Creative Commons Attribution license (http://creativecommons.org/licenses/by/3.0/). 